\title{
A OCORRÊNCIA DO MUTUALISMO FACULTATIVO ENTRE DYCKIA MARITIMA BACKER (BROMELIACEAE) E O CUPIM CORTARITERMES SILVESTRII(HOLMGREN), NASUTITERMITINAE, EM AFLORAMENTOS ROCHOSOS NO PARQUE ESTADUAL DE ITAPUÃ, VIAMÃO, RS ${ }^{1}$
}

\author{
Celso Copstein Waldemar ${ }^{2}$ \\ Bruno Edgar Irgang ${ }^{3}$
}

Recebido em 18/09/1998. Aceito em 10/12/2001

\begin{abstract}
RESUMO - (A ocorrência do mutualismo facultativo entre Dyckia maritima Backer (Bromeliaceae) e o cupim Cortaritermes silvestrii (Holmgren), Nasutitermitinae, em afloramentos rochosos no Parque Estadual de Itapuã, Viamão, RS). A presença de colônias de $C$. silvestrii é comum nos lajeados existentes em Itapuã. Na estação Morro da Grota $_{1}, 92,0 \%$ dos termiteiros situados na rocha exposta e em ilhas de vegetação estão associados a $D$. maritima. Esta convivência ocorre em $31,2 \%$ das ilhas na qual esta bromélia se faz presente. Nas ilhas, a comparação entre os substratos aonde D. maritima vegeta, o solo litólico húmico existente sob o manto do musgo Campylopus spp. e o substrato constituído pelo cupinzeiro indica que este último possui os teores mais elevados dos nutrientes $\mathrm{P}$, $\mathrm{K}, \mathrm{Ca}, \mathrm{Mg}, \mathrm{Zn}$ e Mn, maior CTC e maiores teores de partículas finas, principalmente o silte. O estabelecimento de D. maritima sobre os termiteiros de grande porte aumenta o seu valor de cobertura em ilhas de vegetação quando comparado com ilhas sem termiteiros ou com termiteiros de pequeno porte em áreas entre 2,7 a $8,0 \mathrm{~m}^{2}$. Este fato é atribuído à melhoria físico-química do substrato e ao aumento de superfície e volume aptos a serem colonizados pela bromélia e proporciona maior competitividade em relação a outras espécies vegetais. As características apresentadas pela interação entre este cupim e D. maritima, pela primeira vez descrita na literatura, permitem indicar esta relação ecológica como mutualismo facultativo. Inferimos que o conjunto de observações apresentado constitui um modelo temporal de crescimento deste mutualismo, cujas fases inicial e tardia estão descritas neste trabalho.
\end{abstract}

Palavras-chave - Mutualismo, Dyckia maritima, Bromeliaceae, Cortaritermes silvestrii, Nasutitermitinae

\begin{abstract}
The occurrence of facultative mutualism between Dyckia maritima Backer (Bromeliaceae) and the termite Cortaritermes silvestrii (Holmgren), Nasutitermitinae, on rock outcrops in Itapuã State Park, Viamão, RS). The presence of colonies of $C$. silvestrii is common, both on the rock surface and at islands of vegetation. At Morro da Grota station, 92,0\% of the termite nests on rocky outcrops and at island of vegetation are associated with this bromeliad. These nests are associated with D. maritima, in $31,2 \%$ of the islands where this bromeliad occurs. At these island communities, the comparison between the substrata where D. maritima occurs, the litolic
\end{abstract}

\footnotetext{
Parte da Dissertação de Mestrado do primeiro Autor

Av. Lucas de Oliveira 2658/306. CEP 90460-000, Porto Alegre, RS, Brasil (Celsocw@.ig.com.br)

Departamento de Botânica, UFRGS Av. Paulo Gama 110, CEP 91040-060, Porto Alegre, RS, Brasil
} 


\begin{abstract}
humic soil existing under the mantle of the moss Campylopus spp. and the substratum produced by termites indicates that this possesses higher levels of the nutrients $\mathrm{P}, \mathrm{K}, \mathrm{Ca}, \mathrm{Mg}, \mathrm{Zn}$ and $\mathrm{Mn}, \mathrm{CEC}$ and higher fine particles content, mainly silt. The establishment of $D$. maritima rosettes on great termite nests increase their value of relative coverage at islands inside areas between 2,7 to $8,0 \mathrm{~m}^{2}$. This fact is attributed to the improvement physicalchemistry of the substratum and the increase of surface and volume to be colonized for the Bromeliad. It provides for greater competitiveness at this species in relation to other vegetal species. The features presented for the interaction between this termite and D. maritima, for the first time described in literature, lead to the classification of this ecological relationship as facultative mutualism. The set of observations constitute a temporal model of development of this mutualism at island's vegetation, whose phases, initial and advanced are described.
\end{abstract}

Key words - Mutualism, Dyckia maritima, Bromeliaceae, Cortaritermes silvestrii, Nasutitermitinae

\section{Introdução}

Ao se percorrer os diversos afloramentos rochosos existentes em locais ensolarados no interior do Parque Estadual de Itapuã, percebe-se a freqüente presença de um conjunto de espécies vegetais que se instala em ambientes semelhantes entre si. Trata-se geralmente de um habitat com extrema carência de água, já que a sua capacidade de retenção é mínima apesar das chuvas bem distribuídas ao longo do ano. As espécies que conseguem sobreviver não ocorrem casualmente, mas sim por fatores relacionados com a sua adaptação a esta carência. Entre estas espécies destacam-se Dyckia maritima, Aechmea recurvata (Bromeliaceae) e o musgo Campylopus spp. (Dicranaceae) pela capacidade de colonizarem diretamente a superfície rochosa. O estabelecimento destas espécies pioneiras resulta na melhoria das condições ambientais do sítio, permitindo a instalação de novas espécies e na ocorrência de padrões de agrupamentos fisionomicamente diferenciados. A comunidade de ilhas de vegetação é constituída por agrupamentos de plantas existentes sobre um afloramento rochoso, cuja borda é totalmente delimitada por um substrato pétreo e que fisionomicamente forma um manto vegetal denso sobre a rocha. As espécies com maior cobertura vegetal desta comunidade são Campylopus spp. e Dyckia maritima (Waldemar,1998).

Este gênero, devido a sua capacidade de multiplicação vegetativa, pode colonizar pequenas saliências do terreno. Winkler \& Irgang (1979) relatam o crescimento de Dyckia brevifolia em basalto puro, na margem do rio Uruguai, no Parque Estadual do Turvo, em Derrubadas, RS, em forma de tufos hemisféricos de até meio metro de altura. Estes montículos superficiais são formados por depósitos de cascalho trazidos pela correnteza e que paulatinamente são cobertos pelas plantas.

A associação mutualista mais estudada entre insetos eusociais e angiospermas ocorre com formigas e é conhecida como mirmecofilia. Os gêneros de bromélias Tillandsia e Aechmea são exemplos citados na literatura (Benzing 1970; Madison 1979). No estudo da vegetação dos afloramentos graníticos do leste da Bolívia, Ibisch et al. (1995) constataram a presença de cupinzeiros, e que estes eram usados como substrato por elementos arbóreos e arbustivos na maioria das comunidades rupestres. Segundo estes autores, os ninhos podem influenciar a sucessão vegetal pela acumulação de nutrientes e pela ventilação dos solos. Pelo mesmo motivo, são importantes nas savanas úmidas diferenciando a vegetação pela melhoria no solo e na formação do relevo. As condições do solo proporcionadas pelos cupinzeiros permitem, nesta região da Bolívia, o crescimento de árvores dos gêneros Cochlospermum (Cochlospermaceae), Qualea (Vochysiaceae) e Commiphora leptopholoeos (Burseraceae) entre outras .

Figueira (1989) e Figueira \& Vasconcellos 
Neto (1992) estudaram a associação entre Paepalanthus bromelioides (Eriocaulaceae) e as térmitas dos gêneros Nasutitermes, Vellocitermes, Armitermes e Spinitermes nos campos rupestres da Serra do Cipó, MG. Esta planta tem semelhança morfológica com as bromélias, principalmente pelo caule pouco desenvolvido e envolto por uma roseta foliar. No local, freqüentemente instala-se sobre o ninho de até $30 \mathrm{~cm}$ de altura e de forma cilíndrica.

A associação entre cupins e $P$. bromelioides é provavelmente do tipo mutualista, segundo estes autores, pelas seguintes características: os cupins diminuem a quantidade de material combustível da roseta e misturam ao solo seus excrementos ricos em nutrientes, reduzindo os danos causados pelos freqüentes incêndios naturais ou de origem antrópica que ocorrem na região; estes insetos obtêm da planta alimento constantemente renovado e um microclima mais estável e ameno, quando comparado ao ambiente circundante (Figueira \& Vasconcellos Neto 1992). A maior concentração de nutrientes não contribui, no entanto, para que $P$. bromelioides invista mais em sua reprodução (medida pela biomassa de sua inflorescência) ou no crescimento das rosetas.

Em Itapuã, verificou-se a presença de ninhos de cupins em diversas áreas de afloramentos no parque. Desenvolvem-se principalmente em ilhas de vegetação, em fendas alargadas, na rocha nua e na borda de afloramentos sobre o solo. Observou-se também que D. maritima, Dodonaea viscosa (Sapindaceae), Myrciaria cuspidata (Myrtaceae) e Lithraea brasiliensis (Anacardiaceae) utilizam estes ninhos como substrato de seus sistemas radiculares.

Este trabalho tem como objetivo avaliar as propriedades físicas e químicas do substrato constituído pelo cupinzeiro e do solo litólico existente em ilhas de vegetação, descrever a relação ecológica entre $C$. silvestrii e D. maritima e caracterizar os benefícios mútuos advindos da sua interação.

\section{Material e métodos}

O Parque Estadual de Itapuã está localizado no distrito de mesmo nome, no município de Viamão, pertencente à área metropolitana de Porto Alegre, no estado do Rio Grande do Sul (Fig. 1). O Parque possui 5.333 ha, a maior parte ocupada por uma planície de formação recente (Fujimoto 1994).

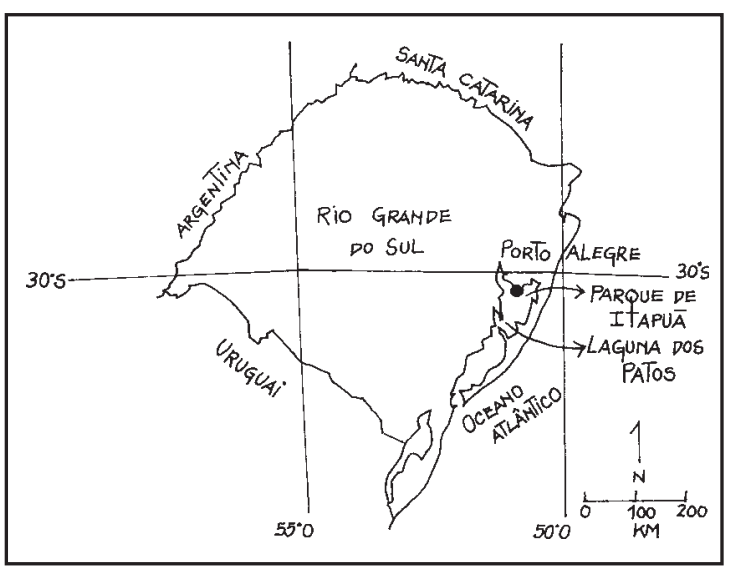

Figura 1. Mapa com a localização do Parque Estadual de Itapuã em Viamão no Estado do Rio Grande do Sul.

Coexistem no parque as formas de relevo tipicamente associadas ao Escudo Sul-riograndense (a porção do Complexo Cristalino localizado no estado) e a Planície Costeira. A primeira província é representada no parque pelas coxilhas e morros com altitude geralmente entre 50 e $200 \mathrm{~m}$. A planície costeira é caracterizada pelas extensas superfícies praticamente horizontais e planas ou levemente onduladas. Nos morros do embasamento cristalino de Itapuã predomina o Sieno-granito, uma rocha granitóide. O clima local enquadra-se no tipo macroclimático subtropical úmido identificado como "Cfa" do sistema de Köppen (Vieira 1984; Fujimoto 1994).

A estação Morro da Grota $\left(\mathrm{MG}_{1}\right)$ foi escolhida para o estudo populacional destas duas espécies pois este lajeado apresentou o maior número de ilhas de vegetação e de ninhos de C. silvestrii entre todos os locais visitados no 
parque. Foi realizado o levantamento de todas as suas 93 ilhas de vegetação e dos 23 ninhos localizados nestas ilhas. Suas coordenadas geográficas são $51^{\circ} 01^{\prime} 15^{\prime}$ ' W, 30 $21^{\circ}$ ' $46^{\prime \prime}$ S. e está situado em um topo secundário, a cerca de $131 \mathrm{~m}$ de altitude. Outras duas áreas de afloramento, com ilhas de vegetação, a cerca de $3 \mathrm{~km}$ desta estação, no topo do Morro do Araçá foram estudadas: estações $\mathrm{MA}_{1}\left(30^{\circ} 21^{\prime} \mathrm{S} ; 51^{\circ} 02^{\prime} \mathrm{W}\right)$ e $\mathrm{MA}_{2}\left(30^{\circ} 21^{\prime} 05 \mathrm{~S} ; 51^{\circ} 02^{\prime} 11 \mathrm{~W}\right)$.

Considerou-se cada ilha de vegetação uma unidade natural. Devido à diversidade de formas observadas nas ilhas estudadas não foi encontrado um padrão morfológico dominante, ao contrário de Meirelles (1990), que encontrou a elipsóide como o formato geral das comunidades insulares dos afloramentos rochosos do litoral da região sudeste brasileira. Foi calculada a área aproximada de cada unidade, (identificada simplificadamente como "área"). Esta área foi determinada através do produto de dois diâmetros perpendiculares, um tomado ao maior comprimento da unidade insular (D1) e o outro, passando pela maior largura deste (D2).

Foram definidos dois substratos, Cupinzeiro e Solo litólico sujeito a ação do fluxo hídrico laminar, quanto às suas características físicoquímicas e para cada tipo foi coletada uma amostra. Estas foram coletadas na ilhas de vegetação de número 18 . O cupinzeiro amostrado está colonizado por D. maritima. As amostras foram encaminhadas ao Laboratório de Análise de Solos da Faculdade de Agronomia da UFRGS para análises texturais e químicas, segundo a metodologia descrita por Tedesco et al.(1985) adotada pela Rede oficial de laboratórios de análise de solos -RS/SC(Siqueira et al. 1987). A interpretação dos resultados analíticos segue os critérios propostos por esta rede.

A descrição quantitativa da comunidade insular em $\mathrm{MG}_{1}$ foi realizada através do registro da sua cobertura, através de estimativa visual no dia 26 de outubro de 1996, tendo-se como base a metodologia de Braun-Blanquet (1979). A escala de cobertura desse autor foi adaptada para a seguinte escala: 1: qualquer número de indivíduos cobrindo mais que $3 / 4$ da área; 2 : qualquer número, cobrindo de $1 / 2$ a $3 / 4$ da área; 3: qualquer número, cobrindo de $1 / 4$ a $1 / 2$ da área; 4: qualquer número, cobrindo de $1 / 10 \mathrm{a}$ 1/4 da área; 5: qualquer número, cobrindo de 1/100 a 1/10 da área; 6: qualquer número, cobrindo até 1/100 da área; 0 : ausência da espécie. Para o processamento destes dados, os símbolos da escala foram transformados no valor da cobertura média de cada classe $(1=87,5 \%, 2=62,5 \%, 3=37,5 \%, 4=17,5 \%$, $5=5,0 \%$ e $6=0,1 \%$ ). Os dados de cobertura das espécies presentes nas ilhas de vegetação foram utilizados no teste de hipóteses via aleatorização, através dos Softwares MULTIV (Pillar 1995). Este teste foi aplicado segundo metodologia de Pillar \& Orlóci (1996).

\section{Resultados e discussão}

Caracterização físico-química dos substratos cupinzeiro e solo litólico presentes em ilhas de vegetação na estação Morro da Grota - Duas categorias de substratos edáficos foram encontrados na comunidade insular em $\mathrm{MG}_{1}$ :

1. Solo litólico húmico sujeito à ação do fluxo hídrico laminar

Este é um dos primeiros substratos formados a partir da instalação de Campylopus spp. sobre o Sieno-granito e que ocorre na maioria das ilhas estudadas. O fluxo laminar, oriundo das precipitações atmosféricas, devido à baixa velocidade com que impacta as ilhas de vegetação, ocasiona, na solução do solo, pouca lixiviação dos elementos e compostos químicos presentes. Neste solo, sobre o manto de Campylopus spp. tipicamente inicia-se o desenvolvimento de populações clonais de D. maritima .

Os solos litólicos são rasos, pouco desenvolvidos e com horizonte A sobre a rochamatriz ou sobre o horizonte $\mathrm{C}$ pouco 
desenvolvido. Localizam-se nas áreas com relevo fortemente ondulado ou montanhoso, assim como nas áreas elevadas próximas às escarpas. Apresentam-se acentuadamente bem drenados. Os solos litólicos húmicos possuem em geral mais de 4,0 \% de carbono orgânico (Moser 1990).

Nas ilhas com D. maritima, o solo litólico ocorre geralmente na sua região periférica, como é o caso da ilha 18. É um solo com acidez elevada, e possui teores elevados dos nutrientes $\mathrm{P}$ e $\mathrm{K}$, teores médios de $\mathrm{S}$ e teores baixos dos demais nutrientes (Tab. 1) Possui nível alto de Al e baixo de Mn (metais fitotóxicos) e contém níveis altos de $\mathrm{C}$ e matéria orgânica. Sua capacidade de troca de cátions (CTC) é média e possui baixa porcentagem de saturação de bases no seu CTC. Caracteriza-se fisicamente por seu elevado teor de areia grossa e grânulos de quartzo.

\section{Cupinzeiro}

A comparação entre o solo litólico e o substrato cupinzeiro encontrados na ilhas de vegetação estudadas em $\mathrm{MG}_{1}$ indica que o cupinzeiro possui os teores mais elevados dos nutrientes $\mathrm{P}, \mathrm{K}, \mathrm{Ca}, \mathrm{Mg}, \mathrm{Zn}$ e $\mathrm{Mn}$, baixo teor de $\mathrm{Al}$ (fitotóxico), e a menor acidez ativa e potencial (avaliado pelo $\mathrm{pH}$ e índice SMP, respectivamente). O cupinzeiro possui elevada CTC, elevada saturação do CTC com bases e predomina o silte.

A granulometria do substrato amostrado em Itapuã é bastante similar ao termiteiro analisado por Figueira (1989); cujos teores de areia grossa, areia fina, silte e argila são de 15, 23, 52 e $10 \%$, respectivamente. As análises de solo de termiteiros associados a Paepalanthus bromelioides (Ericaulaceae) nos campos rupestres da Serra do Cipó, MG, demonstraram composição granulométrica e teores de nutrientes diferentes dos encontrados no solo ao redor. São mais elevados especialmente os teores de $\mathrm{P}, \mathrm{Ca}, \mathrm{Mg}$, e Na. Os dados obtidos, confirmam as informações de Figueira (1989) e Ibisch et al. (1995) quanto à acumulação de nutrientes e
Tabela 1. Caracterização físico-química de solos e de cupinzeiro localizados em ilhas de vegetação em $\mathrm{MG}_{1}$ no Parque Estadual de Itapuã, Viamão, RS (média de duas repetições).

\begin{tabular}{lll}
\hline Determinação & $\begin{array}{l}\text { Solo } \\
\text { litólico } \\
\text { (IV 18)* }\end{array}$ & $\begin{array}{l}\text { Solo } \\
\text { orgânico } \\
\text { (IV 63) }\end{array}$ \\
\hline
\end{tabular}

\begin{tabular}{|c|c|c|c|}
\hline \multicolumn{4}{|l|}{ Análise química } \\
\hline $\mathrm{P} \quad(\mathrm{ppm})$ & 51 & 25 & 64 \\
\hline $\mathrm{K} \quad(\mathrm{ppm})$ & 137 & 131 & 202 \\
\hline $\mathrm{Al}(\mathrm{me} / \mathrm{dl})$ & 2,3 & 2,4 & 0,7 \\
\hline $\mathrm{Ca}(\mathrm{me} / \mathrm{dl})$ & 0,2 & 0,4 & 7,5 \\
\hline $\mathrm{Mg}(\mathrm{me} / \mathrm{dl})$ & 0,1 & 0,1 & 3,5 \\
\hline $\mathrm{S} \quad(\mathrm{ppm})$ & 26,4 & 34,0 & 24,4 \\
\hline $\mathrm{Zn} \quad(\mathrm{ppm})$ & 2,6 & 4,2 & 11,8 \\
\hline $\mathrm{Cu} \quad(\mathrm{ppm})$ & 0,1 & 0,6 & 0,1 \\
\hline B $\quad(p p m)$ & 0,8 & 0,6 & 0,6 \\
\hline $\mathrm{Mn}(\mathrm{ppm})$ & 7 & 5 & 149 \\
\hline Carbono orgânico (- \%) & 9,4 & 20 & 19 \\
\hline Matéria orgânica (- \%) & 16,2 & 34,4 & 32,7 \\
\hline $\mathrm{pH}$ & 4,1 & 4,0 & 4,7 \\
\hline Índice SMP & 4,3 & 4,4 & 4,7 \\
\hline CTC (me/dl) & 9,9 & 9,2 & 18,0 \\
\hline $\begin{array}{r}\text { Saturação do CTC } \\
\text { com bases (\%) }\end{array}$ & 6,6 & 9,0 & 63,9 \\
\hline \multicolumn{4}{|l|}{ Análise física } \\
\hline $\begin{array}{l}\text { Densidade }(\mathrm{g} / \mathrm{ml}) \\
\text { Capacidade Máxima de }\end{array}$ & 1,0 & 0,5 & 0,8 \\
\hline Retenção de Umidade (- \%) & 24 & 53 & 33 \\
\hline \multicolumn{4}{|l|}{ Análise Granulométrica } \\
\hline Areia grossa (- \%) & 46 & 25 & 9 \\
\hline Areia fina (- \%) & 13 & 8 & 21 \\
\hline Silte (- \%) & 24 & 48 & 51 \\
\hline Argila (- \%) & 17 & 19 & 19 \\
\hline
\end{tabular}

* Solo litólico húmico sujeito à ação do fluxo hídrico laminar. Laboratório de solos, UFRGS, 1997.

melhoria das propriedades físicas do substrato edáfico elaborado pelas térmitas.

Relação ecológica entre Dyckia maritima e o cupim Cortaritermes silvestrii na estação Morro da Grota $_{1}$ - Os aspectos demográficos desta relação estão apresentados na Tab. 2. Em $\mathrm{MG}_{1}$ ocorrem 93 ilhas de vegetação cujas áreas variam de $0,0016 \mathrm{~m}^{2}$ a $91,3 \mathrm{~m}^{2}$ (Fig. 2) D. maritima ocorre em 48 ilhas $(51,6 \%$ das ilhas estudadas). Estas ilhas possuem áreas entre 
Tabela 2. Ilhas de vegetação por ordem crescente de área, Cobertura de $D$. maritima por ilha, número de termiteiros por ilha, ocorrência simultânea das duas espécies em cada ilha na estação Morro da Grota ${ }_{1}$ no Parque Estadual de Itapuã, Viamão-RS.

\begin{tabular}{|c|c|c|c|c|c|}
\hline \multirow[t]{2}{*}{ Ilha } & \multirow[t]{2}{*}{$\begin{array}{l}\text { Área } \\
\left(\mathrm{m}^{2}\right)\end{array}$} & \multirow[t]{2}{*}{$\begin{array}{l}\text { Cobertura de } \\
\text { D. maritima }\end{array}$} & \multicolumn{2}{|c|}{$\begin{array}{l}\text { Presença de } \\
D . \text { maritima } \\
\text { termiteiro }\end{array}$} & \multirow[t]{2}{*}{$\begin{array}{l}\text { N. termiteiros } \\
\text { por ilha }\end{array}$} \\
\hline & & & sem & sobre & \\
\hline 62 & 0,0248 & 4 & $\mathrm{X}$ & & 0 \\
\hline 33 & 0,04 & 2 & $\mathrm{X}$ & & 0 \\
\hline 55 & 0,07 & 3 & $\mathrm{X}$ & & 0 \\
\hline 48 & 0,0912 & 4 & $X$ & & 0 \\
\hline 7 & 0,2016 & 3 & $\mathrm{X}$ & & 0 \\
\hline 73 & 0,3456 & 1 & $\mathrm{X}$ & & 0 \\
\hline 11 & 0,399 & 5 & $X$ & & 0 \\
\hline 3 & 0,45 & 4 & $\mathrm{X}$ & & 0 \\
\hline 13 & 0,583 & 3 & $X$ & & 0 \\
\hline 45 & 0,658 & 2 & $\mathrm{X}$ & & 0 \\
\hline 40 & 0,703 & 3 & $\mathrm{X}$ & & 0 \\
\hline 10 & 0,76 & 3 & $\mathrm{X}$ & & 0 \\
\hline 63 & 0,847 & 1 & $X$ & & 0 \\
\hline 19 & 1,1712 & 3 & $X$ & & 0 \\
\hline 6 & 1,2168 & 6 & $X$ & & 0 \\
\hline 50 & 1,41 & 3 & X & & 0 \\
\hline 64 & 1,496 & 2 & $X$ & & 0 \\
\hline 38 & 1,5225 & 3 & $\mathrm{X}$ & & 0 \\
\hline 5 & 1,6005 & 1 & & $X$ & 1 \\
\hline 81 & 1,9712 & 3 & $\mathrm{X}$ & & 0 \\
\hline 2 & 2,325 & 2 & $\mathrm{X}$ & & 0 \\
\hline 24 & 2,3326 & 3 & $X$ & & 0 \\
\hline 49 & 2,3912 & 2 & $\mathrm{X}$ & & 0 \\
\hline 46 & 2,5088 & 4 & $\mathrm{X}$ & & 0 \\
\hline 59 & 2,6772 & 2 & $\mathrm{X}$ & & 0 \\
\hline 43 & 3,0849 & 3 & & $X$ & 1 \\
\hline 69 & 3,289 & 3 & $\mathrm{X}$ & & 0 \\
\hline 1 & 3,36 & 2 & $\mathrm{X}$ & & 0 \\
\hline 70 & 3,525 & 3 & $\mathrm{X}$ & & 0 \\
\hline 39 & 3,7947 & 3 & $X$ & & 0 \\
\hline 28 & 4,0166 & 4 & $\mathrm{X}$ & & 0 \\
\hline 51 & 4,4688 & 3 & & $X$ & 1 \\
\hline 44 & 4,8233 & 1 & $X$ & & 0 \\
\hline 23 & 6,3244 & 4 & & $X$ & 1 \\
\hline 4 & 6,9264 & 2 & & $X$ & 1 \\
\hline 18 & 7,37 & 2 & & $X$ & 1 \\
\hline 34 & 7,959 & 2 & $\mathrm{X}$ & & 0 \\
\hline 60 & 9,2616 & 1 & & $X$ & 2 \\
\hline 58 & 13,728 & 2 & $\mathrm{X}$ & & 0 \\
\hline 22 & 15,922 & 3 & & $\mathrm{X}$ & 2 \\
\hline 66 & 20,7336 & 3 & $\mathrm{X}$ & & 0 \\
\hline 20 & 28,5948 & 3 & & $\mathrm{X}$ & 1 \\
\hline 42 & 29,1 & 2 & & $X$ & 1 \\
\hline
\end{tabular}

Tabela 2 (Continuação)

\begin{tabular}{|c|c|c|c|c|c|}
\hline \multirow[t]{2}{*}{ Ilha } & \multirow[t]{2}{*}{$\begin{array}{l}\text { Área } \\
\left(\mathrm{m}^{2}\right)\end{array}$} & \multirow[t]{2}{*}{$\begin{array}{l}\text { Cobertura de } \\
\text { D. maritima }\end{array}$} & \multicolumn{2}{|c|}{$\begin{array}{l}\text { Presença de } \\
\text { D. maritima } \\
\text { termiteiro }\end{array}$} & \multirow[t]{2}{*}{$\begin{array}{l}\text { N. termiteiros } \\
\text { por ilha }\end{array}$} \\
\hline & & & sem & sobre & \\
\hline 54 & 29,5375 & 2 & & $\mathrm{X}$ & 1 \\
\hline 12 & 43,1969 & 3 & & $\mathrm{X}$ & 5 \\
\hline 29 & 61,662 & 4 & & $\mathrm{X}$ & 1 \\
\hline 67 & 66,429 & 2 & & $\mathrm{X}$ & 1 \\
\hline 16 & 91,278 & 3 & & $\mathrm{X}$ & 3 \\
\hline \multicolumn{3}{|c|}{ Total 496,1817} & 33 & 15 & 23 \\
\hline
\end{tabular}

$0,0248 \mathrm{~m}^{2}$ e $91,3 \mathrm{~m}^{2}$. O seu valor de cobertura relativa é de 46,0\%. Observou-se a presença de 23 termiteiros em 15 ilhas, todos os termiteiros estão colonizados por D. maritima, que cresce sobre sua superfície. Dois outros termiteiros crescem diretamente sobre a rocha neste lajeado, mas não estão colonizados por esta bromélia. Portanto, considerando-se os ambientes rupestres "rocha exposta" e "ilhas de vegetação" deste local, 92,0\% dos termiteiros destes ambientes estão associados a D. maritima. Esta associação é freqüente, em ambientes rupestres, em toda a região do Parque. Os termiteiros estão presentes em $\mathrm{MG}_{1}$, associados a $D$. maritima, em 31,2\% das ilhas nas quais esta bromélia se faz presente. A altura dos termiteiros variou entre 0,20 a $0,30 \mathrm{~m}$.

Considerando-se a sua ocorrência a partir da ilha 5 (com $1,6 \mathrm{~m}^{2}$ de área), a menor ilha onde ocorre esta associação, a freqüência da associação nas ilhas compreendidas no intervalo de área $1,6 \mathrm{~m}^{2}$ a $91,3 \mathrm{~m}^{2}$ é de $50,0 \%$. Este valor elevado parece indicar a preferência deste inseto em instalar-se, em ilhas maiores que $1,6 \mathrm{~m}^{2}$, junto a esta bromélia, ou a sua maior chance de sobrevivência nestas condições.

Relação entre Campylopus spp. e Dyckia maritima em ilhas de vegetação e os seus benefícios para Cortaritermes silvestrii $\mathrm{O}$ estabelecimento de populações clonais de Dyckia maritima em ilhas de vegetação, constituídas predominantemente por 


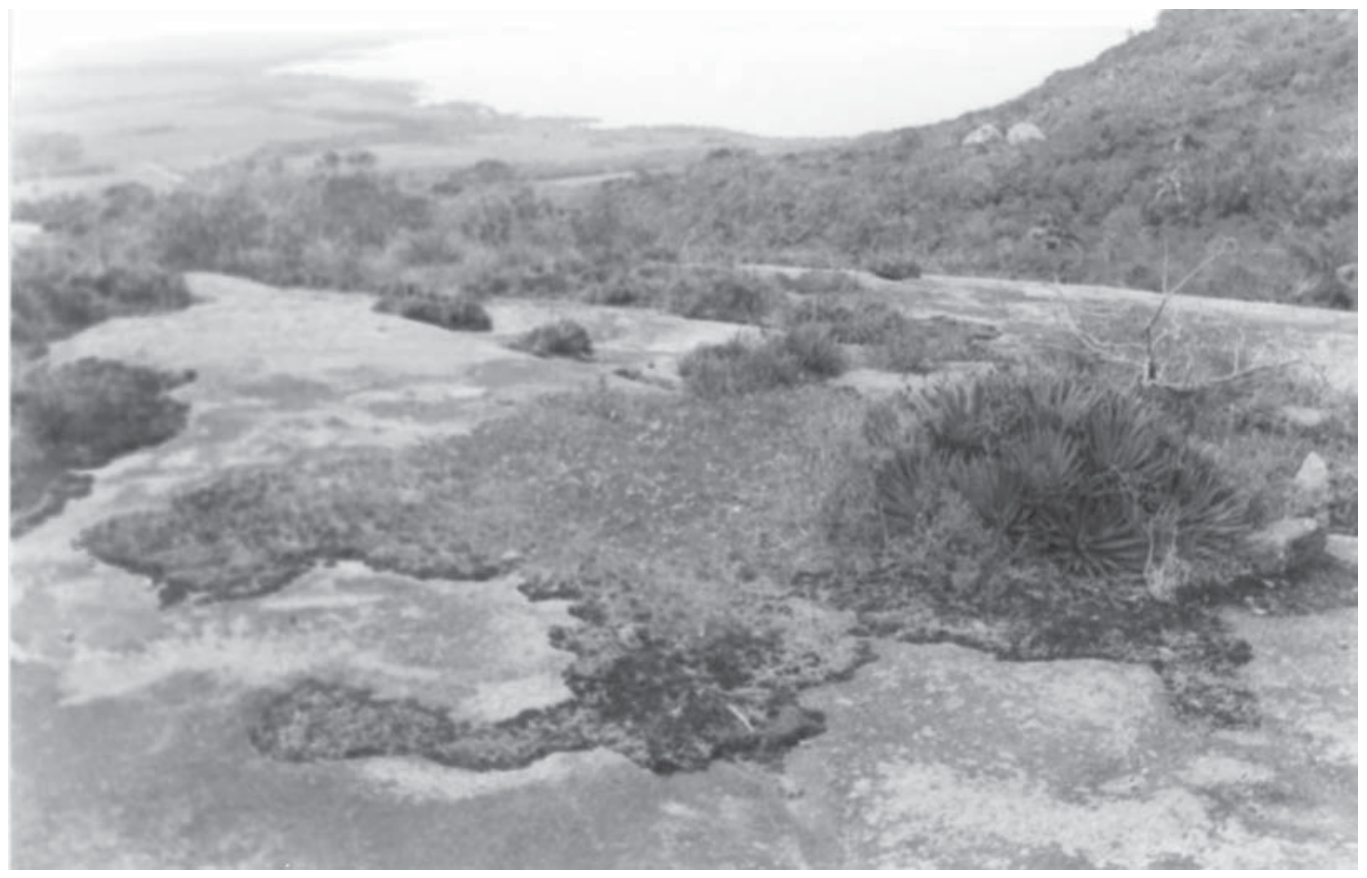

Figura 2. Aspecto da estação Morro da Grota 1 e a presença de ilhas de vegetação recobrindo parcialmente a rocha exposta. No primeiro plano a convivência entre Dyckia maritima e Cortaritermes silvestrii.

Campylopus spp., ocasiona geralmente uma alteração das características do substrato solo litólico. O crescimento desta bromélia é acompanhado do desenvolvimento de grande número de suas raízes adventícias além do perímetro de sua parte aérea, que se espalham subterraneamente sob considerável parte do manto do musgo. Também, à medida que surgem novas folhas junto ao caule, as folhas velhas, bastante fibrosas, entram em senescência. Como resultado, há o aumento da profundidade, da porosidade e principalmente a sua capacidade de retenção de umidade deste substrato, que diferenciado do solo Litólico original, foi denominado Solo Orgânico (Tab. 1). Esse fator é fundamental ao aumento da biomassa vegetal e à sucessão ecológica neste ambiente. Esta melhoria na estrutura do solo praticamente não se altera, mesmo após a senecência destas raízes, pois a sua característica fibrosa e as condições xéricas deste ambiente dificultam a sua decomposição. Provavelmente, a maior oferta de alimento representado pela parte aérea e pelo sistema radicular de D. maritima senescente que se desenvolve sob o manto de Campylopus deve ser um dos motivos para que este cupim colonize exclusivamente ilhas com a presença conjunta destas espécies vegetais e não colonize ilhas sem a presença de Campylopus spp.

A relação causa-efeito da associação entre Dyckia maritima e Cortaritermes silvestrii Qual será o motivo para que todos os termiteiros presentes em ilhas de vegetação em $\mathrm{MG}_{1}$ estejam colonizados por D. maritima e somente aqueles que se desenvolveram sobre a rocha nua não estão colonizados? A resposta a essa pergunta pode esclarecer outra questão: quem se estabeleceu primeiro nas ilhas, o cupim ou a bromélia? Provavelmente $D$. maritima instalase sobre o manto de Campylopus e após o cupim desenvolve seu ninho nas raízes ou no caule da bromélia, aproveitando a disponibilidade de alimentos celulósicos. Como não há termiteiro sem ser colonizado por esta bromélia nas ilhas, 
mas há D. maritima em ilhas sem a presença de termiteiros, D. maritima é a causa da associação e a presença do termiteiro é a conseqüência. É mais provável também que uma sociedade de insetos altamente organizada como C. silvestrii se desloque à procura de um ambiente benéfico do que as sementes transportadas pelo vento de D. maritima vinguem sobre a superfície, por vezes endurecida de um termiteiro.

O primórdio desta associação não foi observado em Itapuã, mas foi constatado pelo primeiro autor com Dyckia encholiriodes e uma espécie não identificada de termita no Parque Estadual da Serra do Tabuleiro, na Praia da Guarda do Embaú, no município de Palhoça, SC. Observou-se a instalação de um termiteiro sobre o grosso e comprido caule prostrado desta bromélia em um "costão rochoso" junto ao mar. No local havia uma população monoespecífica desta planta de cerca de $30 \mathrm{~m}^{2}$. Só foi possível observar este fato devido a ocorrência de um incêndio no local que consumiu as folhas desta bromélia, mas poupou seu caule e raízes. A incidência de dois termiteiros sobre a rocha nua, quando comparados com os 23 termiteiros associados a $D$. maritima existentes nas ilhas em $\mathrm{MG}_{1}$ sugere a existência de benefícios a este inseto.

Benefícios mútuos advindos da associação entre Dyckia maritima e Cortaritermes silvestrii - A convivência entre $C$. silvestrii e D. maritima pode ser melhor compreendida através da análise dos benefícios advindos desta associação facultativa. Na etapa inicial da colonização dos lajeados, este vegetal desenvolve-se sobre mantos de Campylopus spp. É o único substrato disponível, de lenta expansão e que ocupa, geralmente, diminuta parcela da área total de um afloramento. Esta característica dos afloramentos estudados, de ter a maior parte da sua superfície constituída de rocha nua ou coberta apenas de liquens crostosos, aliadas às precárias condições de acúmulo de água dificultam sobremaneira a colonização vegetal.

A presença de um substrato que permita o enraizamento e que retenha água o suficiente para atender a demanda transpiratória entre as precipitações é crucial para o desenvolvimento de plantas vasculares em um afloramento rochoso. O aumento desta biomassa está condicionado, portanto, ao desenvolvimento de um substrato capaz de otimizar a retenção de umidade (Daunbenmire 1968).

Os dados sobre o substrato cupinzeiro quando comparados com o solo litólico húmico, no qual vegeta Campylopus spp., mostram a acumulação de nutrientes e melhoria das propriedades físicas, inclusive o aumento no volume passível de ser explorado pelas raízes de D. maritima.

Existe também o aspecto quantitativo, aumento do número de rosetas foliares, que o termiteiro disponibiliza a $D$. maritima quando se comparam áreas de dimensões similares, conforme foi documentado em duas áreas de afloramento no topo do Morro do Araçá (estações $\mathrm{MA}_{1}$ e $\mathrm{MA}_{2}$ ). Em três ilhas de vegetação, os cupinzeiros, tiveram, em relação aos observados nas demais áreas percorridas no Parque, o seu tamanho aumentado para uma altura de 0,8 a 1,0m e uma área basal de 2,0-4,0m de comprimento por 1,5-2,0m de largura e adquirem, nestas proporções, forma hemisférica ou dómica (Fig. 3 e 4).

Estes ninhos de grande porte, instalados em ilhas, permitem, quando comparados com ilhas sem cupinzeiro mas com mesma área insular, maior número de rosetas desta bromélia por ilha devido ao aumento da superfície externa e ao aumento do volume do substrato colonizado pela planta. Este aumento da superfície do substrato edáfico é importante no ambiente rupestre devido justamente à sua carência na fase inicial da sucessão vegetal. $\mathrm{O}$ aumento de superfície externa, considerando-se a diferença entre um círculo com um raio r e um hemisfério de mesmo raio, ambos de formas perfeitas é de: 


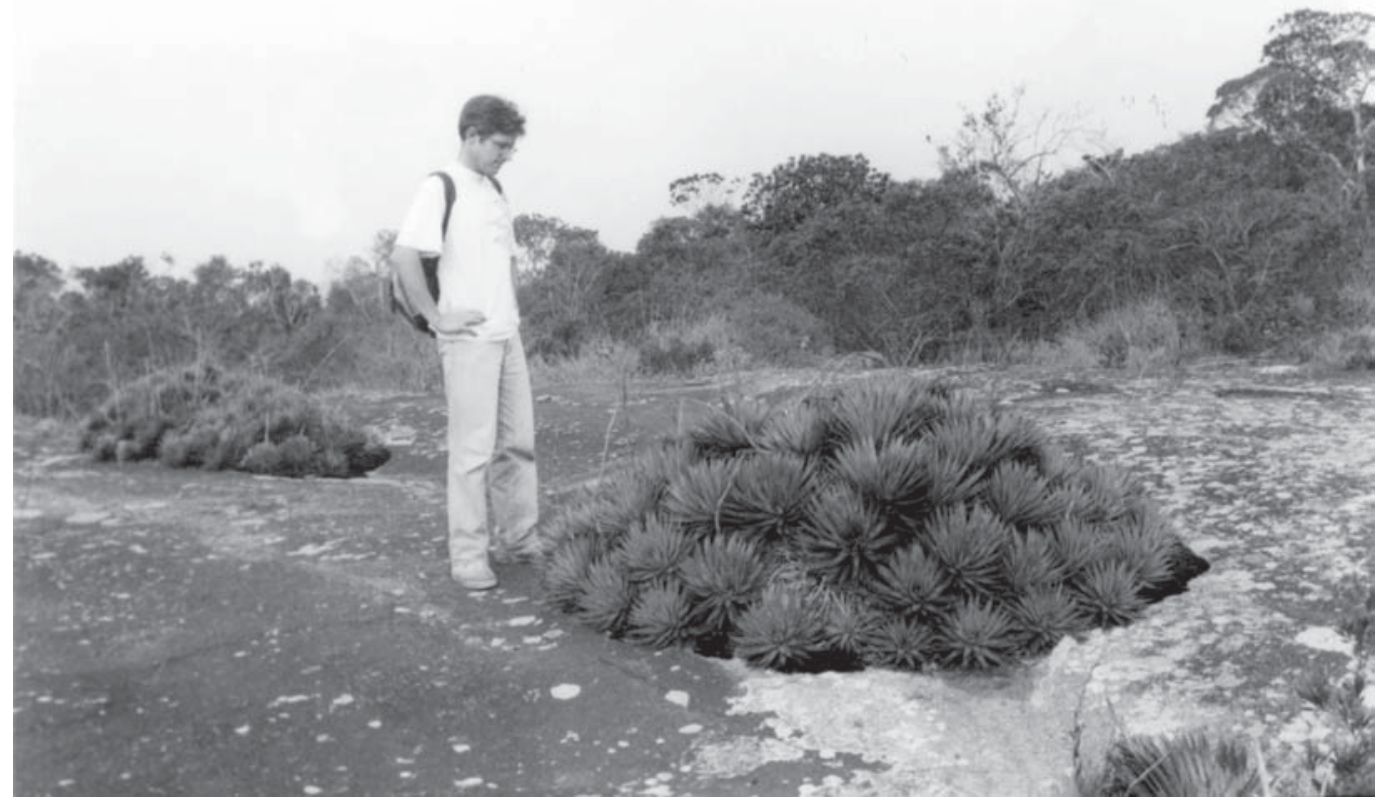

Figura 3. A convivência entre Cortaritermes silvestrii e Dyckia maritima na estação Morro do Araçá em ilhas de vegetação em termiteiros na forma de domo e na forma hemisférica.

(1) superfície da esfera: $4 \pi r^{2}$

(2) superfície de uma calota esférica (hemisfério): $4 \pi r^{2} / 2=2 \pi r^{2}$

(3) Superfície do círculo: $\pi r^{2}$

(4) aumento de superfície externa $(2) /(3)=$ $2 \pi r^{2} / \pi r^{2}=2$

Isto significa que, para termiteiros de forma esférica, a superfície disponível para a colonização de $D$. maritima dobra de tamanho em relação a uma mesma área de superfície plana.

Como forma de avaliar se o estabelecimento desta espécie sobre termiteiros de grande porte aumenta o seu valor de cobertura em ilhas de vegetação de áreas similares, comparou-se: Grupo A, com 3 ilhas que possuem termiteiros de grande porte, presentes em $\mathrm{MA}_{1}$ e $\mathrm{MA}_{2}$ (com áreas de $3,0 \mathrm{~m}^{2}, 3,8 \mathrm{~m}^{2}$ e $7,7 \mathrm{~m}^{2}$ ) com o Grupo B, com 5 ilhas (n. 4, 18, 23, 43 e 51) presentes em $\mathrm{MG}_{1}$ com áreas de 3,0 a $7,4 \mathrm{~m}^{2}$, que possuem termiteiros de até $0,30 \mathrm{~m}$ de altura associados a esta bromélia e com o Grupo C, com 8 ilhas sem a presença de termiteiros (n. 1, 28, 34, 39, 44,
59, 69 e 70) presentes em $\mathrm{MG}_{1}$, com áreas de 2,7 a $8,0 \mathrm{~m}^{2}$. Nas ilhas do grupo A, D. maritima está na classe de cobertura 1 (valor de cobertura de superior a 75,0\%). As classes de cobertura dos grupos 2 e 3 estão apresentados na tabela 2 . A cobertura média de $D$. maritima nos grupos $\mathrm{A}, \mathrm{B}$ e $\mathrm{C}$ é de $87,5 \%, 43,5 \%$ e $50,6 \%$ respectivamente. $\mathrm{O}$ valor da cobertura média desta espécie nas 48 ilhas em que está presente em $\mathrm{MG}_{1}$ é de 46,0\%. Estas 48 ilhas possuem áreas entre $0,0248 \mathrm{~m}^{2}$ e $91,3 \mathrm{~m}^{2}$. As três estações citadas estão localizadas em topos de morros, portanto com a mesma orientação solar. A comparação entre ilhas de áreas similares é de importância na avaliação da cobertura de espécies, pois diminui a possibilidade de comparar ilhas em estádios sucessionais e zonações internas diferenciadas (Waldemar 1998).

A tabela 3 apresenta o teste de hipótese via aleatorização no qual se comparam esses 3 grupos de ilhas entre si. O resultado indicou uma diferença significativa entre os relevés pois $\mathrm{P}(\mathrm{Q}$ rnd $>=$ Qobs $)$ 0,0233, ou seja, a probabi- 


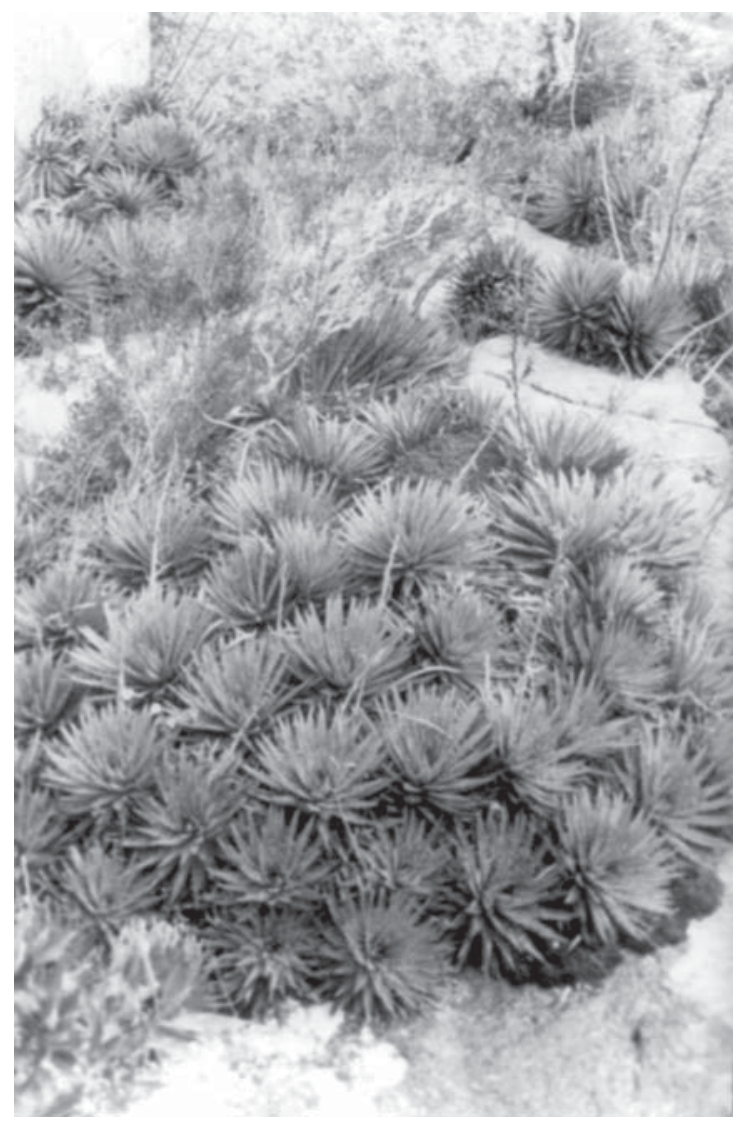

Figura 4. A convivência entre Cortaritermes silvestrii, Dyckia maritima e Myrciaria cuspidata na estação Morro do Araçá ${ }_{2}$ em termiteiro hemisférico.

lidade do critério do teste para os dados aleatórios ser maior ou igual que o critério do teste para os dados observados é de 0,0233 , menor que o nível de significância adotado (a:0,05). Esta diferença no valor de cobertura desta espécie no grupo A em relação aos valores de cobertura nos grupos $\mathrm{B}$ e $\mathrm{C}$ é atribuído à melhoria das condições ambientais proporcionadas por $C$. silvestrii à $D$. maritima e que permite maior competitividade em relação a outras espécies vegetais no ambiente xérico das ilhas de vegetação. Como conseqüência, pode ocorrer o aumento de sua população clonal.

Não há o aumento do tamanho das rosetas conforme avaliação visual realizada, comportamento similar ao observado em Figueira \& Vasconcellos Neto (1992) quando estudaram a
Tabela 3. Teste de hipóteses via aleatorização. Comparação entre a cobertura vegetal de Dyckia maritima em três grupos de ilhas de vegetação: com termiteiros, (a) de grande porte e (b) de pequeno porte e (c) sem termiteiros nas estações Morro do Araçá, Morro do Araçá e Morro da Grota $_{1}$ no Parque Estadual de Itapuã, Viamão, RS. A área insular variou de 2,7 a $8,0 \mathrm{~m}^{2}$. Número de iterações: 3.000 . Critério (lambda) considerado: (1) soma de quadrados das distâncias entre grupos.

\begin{tabular}{rcc}
\hline Fonte de variação & $\begin{array}{c}\text { Soma de } \\
\text { quadrados } \\
\text { (Qobs) }\end{array}$ & $\begin{array}{c}\text { Alfa }+ \text { P } \\
\text { (Qrnd > Qobs) }\end{array}$ \\
\hline Entre grupos & 3981,6 & 0,0233 \\
Contrastes: & & \\
$1-10$ & 3630 & 0,0063 \\
$10-1$ & 2966,8 & 0,0253 \\
$01-1$ & 156,2 & 0,6353 \\
Dentro de grupos & 4866,9 & \\
Total & 8848,4 & \\
\hline
\end{tabular}

associação entre Paepalanthus bromelioides (Eriocaulaceae) e diversos gêneros de térmitas nos campos rupestres da Serra do Cipó, MG.

Quando estas espécies estão associadas, D. maritima dificulta o ataque dos cupinzeiros pelo Tatu, Dasypus spp., (Dasypodidae) devido aos agudos espinhos de suas folhas. As espécies nativas deste mamífero procuram seu alimento escavando e revirando o solo e são predadores naturais de insetos e outros invertebrados (Silva 1984). Em $\mathrm{MG}_{1}$ e em diversas áreas do parque, há sinais da sua presença através de escavações e marca de unhas em cupinzeiros não associados a D. maritima. O fato que os maiores termiteiros encontrados no Parque (localizados nas estações $\mathrm{MA}_{1}$ e $\mathrm{MA}_{2}$ e já descritos) estarem associados a $D$. maritima é um indício que a presença desta bromélia potencializa o seu volume e o crescimento populacional deste inseto. $\mathrm{O}$ resumo dos benefícios advindos desta associação está apresentado na tabela 4 .

Classificação ecológica da relação entre Dyckia maritima e Cortaritermes silvestrii Classicamente, os fenômenos de mutualismo e simbiose são definidos como relações onde há benefício mútuo entre as espécies participantes, 
Tabela 4. Benefícios advindos a cada participante do mutualismo facultativo entre Cortaritermes silvestrii e Dyckia maritima.

Benefícios a D. maritima
Benefícios a C. silvestrii
1. Substrato mais profundo e com maior volume para reter a água da chuva.

2. Substrato com maior riqueza de nutrientes.

3. O cupinzeiro instalado em uma ilha pode proporcionar maior expansão da população clonal desta planta, quando comparado com uma ilha sem estes ninhos, devido à maior área proporcionada pela sua superfície convexa.
1. Fonte de alimentação de folhas e raízes senecentes (celulose) junto ao ninho.

2. Proteção de predadores do gênero Dasypus spp.

3. Pode proporcionar maior volume do termiteiro e de sua população. e que resultam em aumento de suas aptidões em relação àquelas espécies não associadas. Diferem entre si, pois a simbiose envolve intimidade física entre estas espécies, o que implica freqüentemente em alterações estruturais que acomodem esta relação (Boucher et al. 1982; Addicott, apud Figueira 1989).

A simbiose é obrigatória pelo menos para um dos participantes. Já o mutualismo é definido como uma relação na qual não há conexão física, nem tampouco ligações fisiológicas diretas. $\mathrm{O}$ mutualismo pode ser obrigatório, pelo menos para um dos participantes, ou facultativo (Boucher et al. 1982). As características apresentadas pela interação entre estas duas espécies indicam esta relação ecológica como mutualismo facultativo.

Com o inventário dos termiteiros existentes nas ilhas no Morro da Grota $\left(\mathrm{MG}_{1}\right)$ e a descrição do fenômeno de grandes termiteiros crescendo associados a D. maritima no Morro do Araçá $\left(\mathrm{MA}_{1}\right.$ e $\left.\mathrm{MA}_{2}\right)$, inferimos que o conjunto de observações aqui descrito constitui um modelo temporal de crescimento deste mutualismo em ilhas de vegetação, cujas fases inicial e tardia estão representados, respectivamente nas estações destes distintos morros.

\section{Agradecimentos}

A entomóloga Eliane Marques Cancelo, do Museu de Zoologia da USP, pela identificação de Cortaritermes silvestrii.

\section{Referências bibliográficas}

Benzing, D. H. 1970. An investigation of two bromeliad myrmecophytes: Tillandsia butzii Mez. T. caput-medusae E. Morren and their ants. Bulletin of the Torrey Botanical Club 97: 109-115.

Boucher, D. H.; James \& S. \& Keeler, K.H. 1982. The ecology of mutualism. Annual Review of Ecology and Systematics 13: 315-47.

Braun-Blanchet, J. 1979. Fitosociologia: bases para el estudio de las comunidades vegetales. H. Blume Ed., Madri.

Daunbenmire, R. 1968. Plant communities: a textbook of plant synecology. Harper \& Row Ed., Nova Iorque.

Figueira, J. E. C. 1989. Associação entre Paepalanthus bromelioides. Silv. (Eriocaulaceae), aranhas e térmitas. Dissertação de Mestrado. Universidade Estadual de Campinas, Campinas.

Figueira, J. E. C \& Vasconcellos Neto, P. 1992. Paepalanthus, cupins e aranhas. Ciência Hoje, Eco-Brasil (Ed. especial): 89-93.

Fujimoto, N. S. V. M. 1994. Análise geomorfológica de Itapuã-RS: contribuição ao conhecimento da margem norte da Laguna dos Patos. Dissertação de Mestrado. Universidade de São Paulo, São Paulo.

Ibisch, P.L., Rauer \& G., Rudolph, D. 1995. Floristic, biogeographical and vegetational aspects of PréCambrian rock outcrops (inselbergs) in eastern Bolivia. Flora 190: 299-314.

Madison, M. 1979. Additional observations on antgardens in Amazonas. Selbyana 5: 107-115.

Meirelles, S. T. 1990. Ecologia da vegetação de afloramentos rochosos do litoral da região sudeste. Dissertação de Mestrado. Universidade Estadual de Campinas, Campinas.

Moser, J. M. 1990. Solos pp. 81-102. In: Geografia do Brasil: Região Sul. IBGE Ed. Rio de Janeiro. 
Pillar, V. P. 1995. MULTIV: aplicativo para análise multivariada e teste de hipóteses. Universidade Federal do Rio Grande do Sul. Departamento de Botânica (Software). Porto Alegre.

Pillar,V. P. \& Orlóci, L. 1996. On randomization testing in vegetation science: multifactor comparisons of relevé groups. Journal of Vegetation Science 7: 585-592.

Siqueira, O. J. F. (Coordenador). 1987. Recomendação de adubação e calagem para os Estados do Rio Grande do Sul e Santa Catarina. Rede Oficial de Laboratórios de Análise de Solo para os estados do Rio Grande do Sul e Santa Catarina. EMBRAPA Ed., Passo Fundo.

Silva, F. 1984. Mamíferos silvestres - Rio Grande do Sul. Fundação Zoobotânica do Rio Grande do Sul, Ed. Porto Alegre.
Tedesco, M. J.; Volkweiss, S. J. \& Bohnen, H. 1985. Análise de solo, plantas e outros materiais. Universidade Federal do Rio Grande do Sul. Faculdade de Agronomia. Boletim Técnico 5, Porto Alegre.

Vieira, E. F. 1984. Rio Grande do Sul: geografia física e vegetação. Sagra Ed., Porto Alegre.

Waldemar, C. C. 1998. A vegetação rupestre heliófila do Parque Estadual de Itapuã,Viamão, RS. Dissertação de Mestrado. Universidade Federal do Rio Grande do Sul, Porto Alegre.

Winkler, S. \& Irgang, B. E. 1979. Observações ecológicas em bromeliáceas na mata subtropical do Alto Uruguai, Rio Grande do Sul, Brasil. Iheringia Série Botânica 24: 51-60. 